\title{
Valor nutricional da silagem de grãos úmidos de milho com diferentes graus de moagem para leitões na fase de creche
}

\author{
[Nutritional value of high moisture corn silage with differents particle sizes for piglets in nursery phase] \\ M.L.P. Tse ${ }^{1}$, D.A. Berto ${ }^{2}$, C.A. Tofoli ${ }^{1}$, F.S. Wechsler ${ }^{2}$, M.A. Trindade Neto ${ }^{3}$ \\ ${ }^{1}$ Aluno de pós-graduação - FMVZ-UNESP - Botucatu, SP \\ ${ }^{2}$ Faculdade de Medicina Veterinária e Zootecnia - UNESP \\ Caixa Postal 560 \\ 18618-000 - Botucatu, SP \\ ${ }^{3}$ Faculdade de Medicina Veterinária e Zootecnia - USP - Pirassununga, SP
}

\begin{abstract}
RESUMO
Utilizaram-se 72 leitões mestiços (Landrace x Large White), com peso inicial médio de 7,1kg, no experimento de desempenho e 20 leitões mestiços, com peso inicial médio de $18,9 \mathrm{~kg}$, no experimento de digestibilidade para avaliar a silagem de grãos úmidos de milho com diferentes granulometrias para leitões em fase de creche. $\mathrm{O}$ delineamento experimental foi em blocos ao acaso. Em ambos os experimentos avaliaram-se o valor nutricional das silagens com diâmetro geométrico médio (DGM) das partículas de 979, 1168 e $2186 \mu \mathrm{m}$ e do milho seco com DGM das partículas de $594 \mu \mathrm{m}$. Na fase de zero ao oitavo dia, a silagem proporcionou menor consumo diário de ração (CDR) em relação ao milho seco, e foi verificado aumento linear no CDR com o aumento da granulometria da silagem. A silagem com granulometria média e grossa proporcionou melhora na conversão alimentar (CA) em relação ao milho seco, mas não foi observada diferença no ganho diário de peso (GDP). Para o período total, não foram observadas diferenças estatísticas para CDR e GDP, entretanto a silagem proporcionou melhora na $\mathrm{CA}$ em relação ao milho seco havendo efeito linear crescente da granulometria da silagem sobre a CA. A granulometria da silagem não influenciou nos coeficientes de digestibilidade aparente (CDA) da matéria seca e da proteína bruta, porém proporcionou maiores CDA do fósforo e valores de energia digestível em relação ao milho seco. O CDA do cálcio e os valores de energia metabolizável foram maiores para a silagem com granulometria fina e média, comparado ao do milho seco. Houve redução linear do CDA do cálcio com o aumento da granulometria da silagem.
\end{abstract}

Palavras-chave: leitão, silagem, desempenho, digestibilidade, granulometria

\begin{abstract}
Seventy-two crossbred pigs (Landrace $x$ Large White) average initial body weight of $7.1 \mathrm{~kg}$ and 20 crossbred pigs average initial body weight of $18.9 \mathrm{~kg}$ were used in the performance and digestibility experiments to evaluate high-moisture corn silage with different particle sizes for piglets in nursery phase. A randomized block design was used. In both experiments the nutritional values of high-moisture corn silage with 979, 1168 and $2186 \mu \mathrm{m}$ geometric mean particle sizes (GM) and dry corn with $594 \mu \mathrm{m}$ GM were evaluated. From day 0 to 8, high-moisture corn silage provided daily feed intake (ADFI) lower than dry corn. A linear increase was observed to this variable when increasing the particle size of the silage. The silage with intermediate and coarse particle sizes provided higher feed/weight gain than the dry corn, but no difference in average daily gain $(A D G)$ was observed. Throughout the experimental period, there were no statistical differences in ADFI and $A D G$. Therefore, the silage improved feed/weight gain in comparison to the dry corn. There was a linear increase of values of this variable as particle size of the silage increased. No effect of particle size of the silage on the apparent digestibility coefficients (ADC) of dry matter and crude protein was observed. However, it provided higher phosphorus ADC and values of digestible energy than the dry corn. Calcium ADC as well as
\end{abstract}

Recebido em 19 de outubro de 2004

Aceito em 11 de agosto de 2006

E-mail: marcostse@gmail.com

Apoio: FAPESP 
Valor nutricional da silagem de grãos...

values of metabolizable energy increased for silage with fine and intermediate particle sizes in comparison to the dry corn silage. Calcium ADC linearly decreased as the particle size of the silage increased.

Keywords: piglet, silage, performance, digestibility, particle size

\section{INTRODUÇÃO}

A suinocultura moderna vem caminhando com vistas a novas perspectivas de aumento nos índices de produtividade. Essa evolução tem sido devida à melhoria genética e nutricional. A fase de creche é a que representa maior desafio para os nutricionistas, pois é considerada crítica na produção de suínos devido aos vários fatores estressantes.

Em função de o milho participar em 70 a $80 \%$ da composição total da ração de suínos, o correto grau de moagem deste cereal pode ser determinante no custo de produção destes animais. Além disso, o tamanho das partículas de milho desempenha um papel crítico na determinação de sua digestibilidade. Healy et al. (1994) observaram melhora no desempenho de leitões pós-desmame quando o tamanho das partículas de milho e de sorgo foi reduzido. Vários autores relataram que o processamento dos grãos, tais como redução no tamanho das partículas e tratamento com pressão e vapor, afetam a digestão do amido (Galyean et al., 1979; Theurer, 1986; Mello Jr., 1991).

Além da preocupação com a moagem, outras formas de processamento dos alimentos também merecem atenção. A ensilagem de grãos úmidos de milho demonstrou ser uma técnica viável para os suinocultores, uma vez que Lopes et al. (2001a,b) e Oliveira et al. (2004) comprovaram as vantagens da silagem em relação ao milho seco. Considerando que a silagem de grãos úmidos de milho vem se tornando uma alternativa para os produtores de suínos, Nummer Filho (2001) propõe que a granulometria do milho ensilado deve ser fina, sem definir, entretanto qual o DGM das partículas recomendado.

Este trabalho teve o objetivo de avaliar os efeitos do grau de moagem dos grãos úmidos de milho para ensilagem sobre o desempenho $\mathrm{e}$ digestibilidade em leitões na fase de creche.

\section{MATERIAL E MÉTODOS}

Foram utilizados 72 leitões mestiços (Landrace x Large White), com 31 dias de idade e peso inicial médio de $7,1 \mathrm{~kg}$, alojados em baias metálicas suspensas de creche, durante todo o período experimental (31 a 59 dias de idade).

O delineamento experimental foi em blocos ao acaso com seis repetições e os critérios para a formação dos blocos foram o peso, o sexo e a leitegada. Cada unidade experimental foi formada por três leitões que foram aleatoriamente distribuídos aos tratamentos: $\mathrm{T} 1=$ rações à base de grãos de milho seco $(87,1 \%$ de $\mathrm{MS})$ moídos com diâmetro geométrico médio (DGM) das partículas de $594 \mu \mathrm{m} ; \mathrm{T} 2=$ rações à base de silagem de grãos úmidos de milho (66,5\% de MS) moída com DGM das partículas de $979 \mu \mathrm{m} ; \mathrm{T} 3=$ rações à base de silagem de grãos úmidos de milho $(66,5 \%$ de $\mathrm{MS})$ moída com DGM das partículas de $1168 \mu \mathrm{m}$; T4= rações à base de silagem de grãos úmidos de milho (66,5\% de MS) moída com DGM das partículas de $2186 \mu \mathrm{m}$.

Foi utilizado um único híbrido de milho, produzido nas mesmas condições de solo, clima e tratos culturais, para a produção da silagem e do milho seco. Os grãos úmidos foram triturados e ensilados em tambores plásticos de 100 e 200 litros. A moagem do milho seco e úmido foi realizada em moinho do tipo faca com motor de indução trifásico de $60 \mathrm{~Hz}, 25 \mathrm{cv}$ em $3510 \mathrm{rpm}$.

Durante o período experimental (28 dias), foram fornecidas três rações à vontade, sendo ração préinicial nos primeiros oito dias; ração inicial I do $9^{\circ}$ ao $22^{\circ}$ dia e ração inicial II, do $23^{\circ}$ ao $28^{\circ}$ dia. As rações foram formuladas para atender, no mínimo, às exigências nutricionais propostas pelo Nutrient... (1998), exceto para proteína bruta, para cada uma das fases estudadas (Tab. 1). Os teores de matéria seca das silagens foram corrigidos para o mesmo valor de matéria seca do milho seco, e foram utilizados fatores de correção para substituição total do milho seco pelas silagens nas rações. $\mathrm{O}$ milho seco e as silagens foram submetidos à análise de $\mathrm{pH}$. A granulometria das silagens e do milho seco foi realizada segundo a metodologia descrita por Zanotto e Bellaver (1996). 
Tabela 1. Composição percentual e valores calculados das rações fornecidas aos leitões durante o período de creche ${ }^{1}$

\begin{tabular}{|c|c|c|c|}
\hline & $\begin{array}{c}\text { Fase I (1-8 dias) } \\
\%\end{array}$ & $\begin{array}{c}\text { Fase II (9-22 dias) } \\
\%\end{array}$ & $\begin{array}{c}\text { Fase III (23-28 dias) } \\
\%\end{array}$ \\
\hline \multicolumn{4}{|l|}{ Ingrediente } \\
\hline Milho moído & 34,000 & 51,500 & 62,400 \\
\hline Farelo de soja & 22,090 & 25,500 & 27,500 \\
\hline Soro de leite & 20,580 & 10,504 & 0,000 \\
\hline Milho gelatinizado & 9,825 & 0,000 & 0,000 \\
\hline Açúcar & 4,000 & 4,000 & 3,000 \\
\hline Células sanguíneas & 2,800 & 1,830 & 0,000 \\
\hline Fosfato bicálcico & 2,225 & 2,200 & 2,350 \\
\hline Óleo de soja & 2,550 & 2,600 & 2,930 \\
\hline L-Lisina $\mathrm{HCl}$ & 0,485 & 0,410 & 0,530 \\
\hline Calcário calcítico & 0,369 & 0,400 & 0,410 \\
\hline Sal & 0,300 & 0,350 & 0,350 \\
\hline Óxido de zinco & 0,300 & 0,180 & 0,000 \\
\hline DL-Metionina & 0,100 & 0,100 & 0,100 \\
\hline L-Triptofano & 0,040 & 0,025 & 0,030 \\
\hline Cloreto de colina & 0,040 & 0,040 & 0,050 \\
\hline Antioxidante & 0,030 & 0,030 & 0,000 \\
\hline L-Treonina & 0,010 & 0,005 & 0,024 \\
\hline Olaquindox & 0,006 & 0,006 & 0,006 \\
\hline Sulfato de cobre & 0,000 & 0,070 & 0,070 \\
\hline Mistura vitamínica ${ }^{2}$ & 0,150 & 0,150 & 0,150 \\
\hline Mistura mineral $^{3}$ & 0,100 & 0,100 & 0,100 \\
\hline Total & 100,00 & 100,00 & 100,00 \\
\hline \multicolumn{4}{|l|}{ Valores calculados } \\
\hline Energia metabolizável (kcal/kg) & 3284,307 & 3287,110 & 3284,550 \\
\hline Proteína bruta $(\%)$ & 18,891 & 19,080 & 18,060 \\
\hline Cálcio $(\%)$ & 0,838 & 0,810 & 0,800 \\
\hline Fósforo total (\%) & 0,669 & 0,640 & 0,640 \\
\hline Lisina $(\%)$ & 1,492 & 1,350 & 1,260 \\
\hline Metionina (\%) & 0,412 & 0,390 & 0,360 \\
\hline Triptofano $(\%)$ & 0,262 & 0,240 & 0,230 \\
\hline Treonina $(\%)$ & 0,953 & 0,900 & 0,810 \\
\hline
\end{tabular}

${ }^{1} \mathrm{O}$ milho silagem substituiu o milho seco nas rações com base na mesma matéria seca.

${ }^{2}$ Mistura vitamínica/kg/ração: vit.A=9000UI, vit.D3=2250UI, vit.E=22,5mg; vit.K3=2,25mg, vit.B1=2,03mg; vit.B2=6mg, vit.B6 $=3 \mathrm{mg}$, vit. $\mathrm{B} 12=30 \mathrm{mcg}$, ác. fólico $=0,9 \mathrm{mg}$, ác. pantotênico $=14,03$, niacina $=30 \mathrm{mg}$, biotina $=0,12 \mathrm{mg}$.

${ }^{3}$ Mistura mineral/kg/ração: $\mathrm{Fe}=100 \mathrm{mg}, \mathrm{Cu}=10 \mathrm{mg}, \mathrm{Mn}=40 \mathrm{mg}, \mathrm{Zn}=100 \mathrm{mg}, \mathrm{Co}=1 \mathrm{mg}, \mathrm{I}=1,5 \mathrm{mg}$.

O consumo diário de ração e o ganho diário de peso foram calculados, respectivamente, com base na pesagem da ração fornecida diariamente e com base na pesagem dos animais nos dias 0 , 8,22 e 28

$\mathrm{O}$ experimento de digestibilidade foi realizado em fevereiro e março de 2003. Foram utilizados 20 leitões mestiços (Landrace x Large White), machos castrados, com peso inicial médio de $18,9 \mathrm{~kg}$, respectivamente, confinados em gaiolas de metabolismo semelhante às descritas por Pekas (1968). O período experimental teve duração de 13 dias, sendo sete dias de adaptação dos animais às gaiolas e às dietas experimentais, e seis dias de coleta.
O delineamento experimental foi de blocos ao acaso, com cinco tratamentos e quatro repetições. As parcelas (um animal) foram aleatoriamente distribuídas nos tratamentos: $\mathrm{T} 1=$ raçãoreferência $(\mathrm{Tab} .2) ; \mathrm{T} 2=$ mistura composta de $70 \%$ de ração-referência e $30 \%$ de milho seco moído com diâmetro geométrico médio (DGM) das partículas de $594 \mu \mathrm{m} ; \mathrm{T} 3=$ mistura composta de $70 \%$ de ração-referência e $30 \%$ de silagem de grãos úmidos de milho moída com DGM das partículas de $979 \mu \mathrm{m}$; T4= mistura composta de $70 \%$ de ração-referência e $30 \%$ de silagem de grãos úmidos de milho moída com DGM das partículas de $1168 \mu \mathrm{m} ; \mathrm{T} 5=$ mistura composta de $70 \%$ de ração-referência e $30 \%$ de silagem de grãos úmidos de milho moída com DGM das 
partículas de $2186 \mu \mathrm{m}$. As silagens e os milhos secos foram os mesmos usados no experimento de desempenho e substituíram a ração-referência com base na matéria seca. Os demais procedimentos foram realizados conforme Fialho et al. (1979).

Tabela 2. Composição percentual e valores determinados da ração-referência fornecida para os leitões, no experimento de digestibilidade ${ }^{1}$

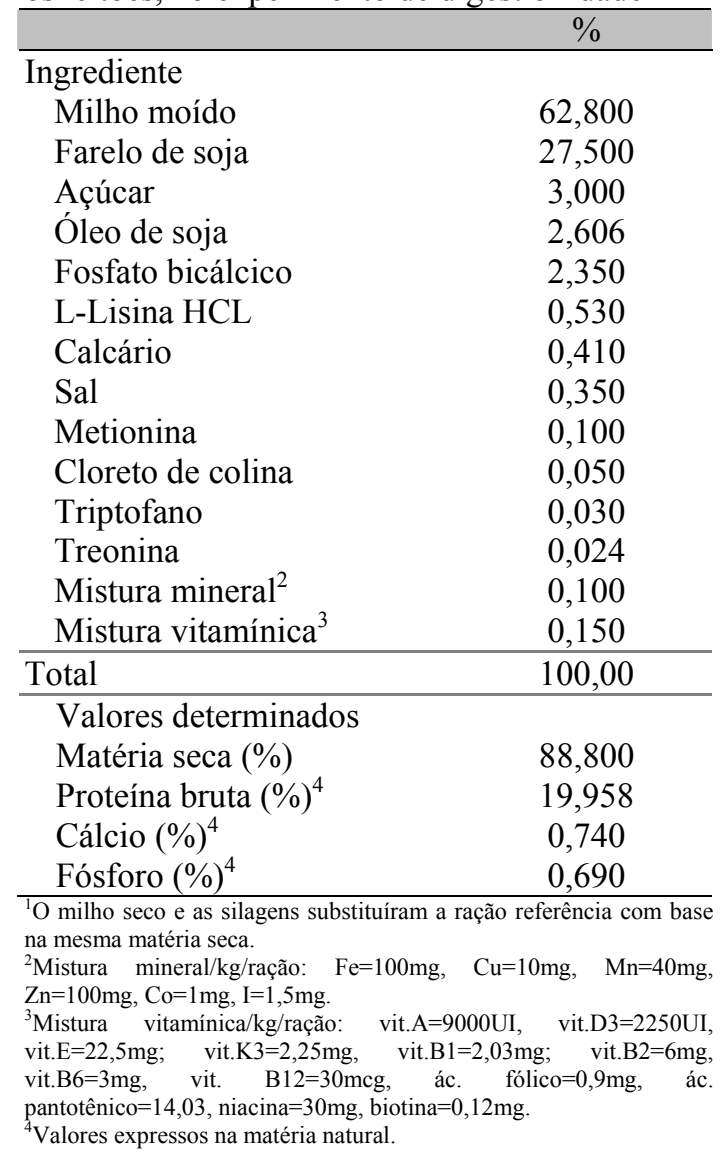

Foram feitas análises da matéria seca, proteína bruta, cálcio, fósforo e energia bruta das fezes e do alimento. $\mathrm{Na}$ urina, foi analisada a energia bruta.

O método de Matterson et al. (1965) foi empregado nos cálculos dos valores dos coeficientes de digestibilidade aparente da matéria seca, proteína bruta, cálcio e fósforo e dos teores de energia digestível e energia metabolizável dos alimentos-teste.

Os dados de desempenho e de digestibilidade foram submetidos à análise de variância e de regressão e as médias comparadas por contrastes e pelo teste de Dunnett, utilizando-se o PROC GLM do SAS (User's..., 1998).

\section{RESULTADOS E DISCUSSÃO}

A composição bromatológica, os valores de $\mathrm{pH}$ e de diâmetro geométrico médio (DGM) das partículas do milho seco moído e das silagens são apresentados na Tab. 3. Na Tab. 4 são apresentados os valores médios das variáveis de desempenho na primeira fase ( 0 a 8 dias) e do período total do experimento (0 a 28 dias). A composição de matéria seca, proteína bruta, cálcio e fósforo do milho seco e das silagens foram semelhantes às descritas pela Embrapa (Tabela..., 1991). Quanto ao pH das silagens e ao DGM do milho seco, estão de acordo, respectivamente, com Shaver (2000) e Zardo e Lima (1999).

$\mathrm{O}$ consumo diário de ração foi menor $(\mathrm{P}<0,05)$ e a conversão alimentar foi melhor $(\mathrm{P}<0,05)$ para os animais que receberam silagem, demonstrando seu maior valor nutricional comparado com o milho seco para leitões.

Tabela 3. Composição bromatológica, valores de pH e de diâmetro geométrico médio (DGM) das partículas das silagens e do milho seco moído

\begin{tabular}{lcccccc} 
Tipo de Milho & MS $(\%)$ & PB $(\%)^{1}$ & Ca $(\%)^{1}$ & P(\%) & pH & DGM $(\mu \mathrm{m})$ \\
\hline Milho seco & 87,11 & 10,55 & 0,049 & 0,260 & 6,10 & 594 \\
Silagem fina & 66,46 & 11,62 & 0,077 & 0,292 & 4,00 & 979 \\
Silagem média & 66,46 & 11,04 & 0,062 & 0,310 & 4,00 & 1168 \\
Silagem grossa & 66,46 & 11,36 & 0,037 & 0,267 & 4,00 & 2186 \\
\hline
\end{tabular}

${ }^{1}$ Valores expressos na matéria seca. 
Tabela 4. Médias de consumo diário de ração (CRD), ganho de peso diário (GPD), e conversão alimentar (CA) dos leitões nos primeiros oito dias e durante todo o período experimental recebendo milho seco e silagens

\begin{tabular}{|c|c|c|c|c|c|c|c|}
\hline \multirow{2}{*}{$\begin{array}{l}\text { Período } \\
\text { (dias) }\end{array}$} & \multirow{2}{*}{ Variável } & \multirow{2}{*}{$\frac{\text { Milho seco }}{594 \mu \mathrm{m}}$} & \multicolumn{3}{|c|}{ Milho silagem } & \multirow{2}{*}{ Efeito linear } & \multirow{2}{*}{ CV (\%) } \\
\hline & & & $979 \mu \mathrm{m}$ & $1168 \mu \mathrm{m}$ & $2186 \mu \mathrm{m}$ & & \\
\hline \multirow{3}{*}{0 a 8} & $\mathrm{CRD}^{1,2}(\mathrm{~g})$ & 626 & $542 *$ & $546^{*}$ & $576^{*}$ & $\mathrm{P}=0,06$ & 5,58 \\
\hline & GPD $(g)$ & 492 & 459 & 493 & 499 & NS $(P>0,06)$ & 7,14 \\
\hline & $\mathrm{CA}$ & 1,29 & 1,19 & $1,11^{*}$ & $1,16^{*}$ & $\mathrm{NS}(\mathrm{P}>0,06)$ & 6,61 \\
\hline \multirow{3}{*}{0 a 28} & $\mathrm{CRD}^{1,2}(\mathrm{~g})$ & 1097 & 976 & 1003 & 1053 & NS $(\mathrm{P}>0,06)$ & 8,22 \\
\hline & GPD $(\mathrm{g})$ & 642 & 667 & 669 & 671 & $\mathrm{NS}(\mathrm{P}>0,06)$ & 6,21 \\
\hline & $\mathrm{CA}$ & 1,71 & $1,46^{*}$ & $1,50 *$ & $1,57^{*}$ & $\mathrm{P}=0,007$ & 3,97 \\
\hline
\end{tabular}

$\mathrm{NS}=$ não significativo, *Diferem em relação ao milho seco $(\mathrm{P}<0,05)$ pelo teste de Dunnett.

${ }^{1}$ Valores corrigidos para a mesma base de matéria seca do milho seco (milho seco $=87,11 \%$ de MS e silagens $=66,46 \%$ de MS). ${ }^{2}$ Milho seco x silagem $(\mathrm{P}<0,05)$.

A comparação das médias de desempenho pelo teste de Dunnet, revelou que os leitões que receberam rações com silagens apresentaram menor $(\mathrm{P}<0,05)$ consumo de ração diário (DGM de 979, 1168 e $2186 \mu \mathrm{m})$ e melhor $(\mathrm{P}<0,05)$ conversão alimentar (DGM de 1168 e $2186 \mu \mathrm{m}$ ) em relação àqueles alimentados com milho seco nos primeiros oito dias do experimento, enquanto que no período total ( 0 a 28 dias) os animais que receberam silagem (DGM de 979, 1168 e $2186 \mu \mathrm{m})$ tiveram melhor $(\mathrm{P}<0,05)$ conversão alimentar.

Quando os resultados dos tratamentos com silagem foram analisados por regressão polinomial, não foram observados efeitos $(\mathrm{P}>0,06)$ da granulometria sobre o ganho de peso diário e conversão alimentar nos primeiros oito dias e sobre o consumo de ração diário e ganho de peso diário no período total do experimento. No período de 0 a 8 dias, o aumento da granulometria da silagem aumentou linearmente $(\mathrm{P}<0,06)$ no consumo de ração diário $\left(\hat{\mathrm{Y}}_{\mathrm{i}}=\right.$ $\left.513,2233+0,0288 \mathrm{X}_{\mathrm{i}}, \mathrm{R}^{2}=0,65\right)$ e no período total, piora linear $(\mathrm{P}=0,0076)$ na conversão alimentar $\left(\hat{\mathrm{Y}}_{\mathrm{i}}=1,3846+0,00009 \mathrm{X}_{\mathrm{i}}, \mathrm{R}^{2}=0,67\right)$.

Segundo Wondra et al. (1996) em muitos experimentos com suínos não são observados melhora no ganho diário de peso, com a diminuição da granulometria das partículas, sendo mais comum a ocorrência de melhora na conversão alimentar.

Não houve diferença no ganho de peso diário $(\mathrm{P}>0,05)$ entre os leitões alimentados com rações de milho seco ou silagem de grãos úmidos de milho, em nenhum dos períodos estudados. Resultado semelhante foi, também, observado por Engelke et al. (1984) quando avaliaram silagem de grãos úmidos de milho para suínos em crescimento e terminação.

A melhora na conversão alimentar dos animais que receberam silagem está de acordo com os resultados obtidos por Lopes et al. (2001a,b), Lopes et al. (2002b) e Tófoli et al. (2006) e pode estar relacionada ao processo de ensilagem que, segundo Lopes et al. (2002a), melhora o valor nutricional do milho, provavelmente em função das alterações estruturais que ocorrem no interior do endosperma dos grãos, como o rompimento da matriz protéica que envolve os grânulos de amido e as alterações nos próprios grânulos. Além disso, os melhores resultados da silagem também podem estar relacionados ao seu menor valor de $\mathrm{pH}$, comparado ao milho seco.

No período total, a melhora linear na conversão alimentar dos leitões com a redução da granulometria da silagem, pode ser atribuída ao fato de que a diminuição do diâmetro geométrico médio das partículas aumenta a superfície de contato dos ingredientes com as enzimas digestivas, melhorando a digestibilidade.

Os valores dos coeficientes de digestibilidade aparente da matéria seca, da proteína bruta, do cálcio, do fósforo e os valores de energia digestível e metabolizável do milho seco e das silagens de diferentes granulometrias são apresentados na Tab. 5. 
Tabela 5. Valores dos coeficientes de digestibilidade aparente da matéria seca (CDMS), da proteína bruta (CDPB), do cálcio (CDCa) e do fósforo (CDP), e valores de energia digestível (ED) e energia metabolizável (EM=kcal/kg/MS) do milho seco e das silagens de diferentes granulometrias

\begin{tabular}{|c|c|c|c|c|c|c|}
\hline \multirow{2}{*}{ Variável } & \multirow{2}{*}{$\frac{\text { Milho seco }}{594 \mu \mathrm{m}}$} & \multicolumn{3}{|c|}{ Milho silagem } & \multirow{2}{*}{ Efeito } & \multirow{2}{*}{ CV $(\%)$} \\
\hline & & $979 \mu \mathrm{m}$ & $1168 \mu \mathrm{m}$ & $2186 \mu \mathrm{m}$ & & \\
\hline $\mathrm{CDMS}^{3}$ & 84,43 & 90,53 & 89,75 & 87,14 & $\mathrm{NS}^{1}$ & 4,25 \\
\hline $\mathrm{CDPB}^{3}$ & 67,81 & 80,58 & 75,05 & 75,58 & NS & 9,23 \\
\hline $\mathrm{CDCa}^{3}$ & 54,25 & $83,33^{*}$ & $86,40 *$ & 63,22 & $\mathrm{P}=0,02^{2}$ & 18,10 \\
\hline $\mathrm{CDP}^{3}$ & 49,01 & $82,53^{*}$ & $80,08^{*}$ & $70,88^{*}$ & NS & 14,84 \\
\hline $\mathrm{ED}^{3}$ & 3755 & $4333 *$ & $4342 *$ & $4163 *$ & NS & 4,91 \\
\hline $\mathrm{EM}^{3}$ & 3635 & $4231 *$ & $4197 *$ & 4031 & NS & 5,38 \\
\hline
\end{tabular}

*Diferem em relação ao milho seco $(\mathrm{P}<0,05)$ pelo teste de Dunnett ${ }^{1}$ Não significativo $(\mathrm{P}>0,05),{ }^{2}$ Efeito linear, ${ }^{3}$ Milho seco $\mathrm{x}$ silagens $(\mathrm{P}<0,05)$.

Para todos os parâmetros avaliados, a média dos valores, observados para as silagens, foi superior à do milho seco $(\mathrm{P}<0,05)$, confirmando o maior valor nutricional da silagem para os leitões.

$\mathrm{O} \mathrm{pH}$ das silagens $(4,0)$ foi inferior ao do milho seco $(6,1)$, o que pode explicar em parte os maiores coeficientes de digestibilidade aparente da silagem. Segundo Berto et al. (2001) e Sartori et al. (2002) a maior acidez do conteúdo estomacal contribui para maior taxa de retenção da digesta no estômago, maior ativação das pepsinas e redução na proliferação de coliformes. Além disso, o processo de ensilagem provoca alterações no endosperma dos grãos, como o rompimento da matriz protéica (Lopes et al., 2001a,b; Lopes et al., 2002a) e modificações estruturais nos grânulos de amido (Lopes et al., 2002a), favorecendo a digestão.

Não houve efeito $(\mathrm{P}>0,05)$ significativo da granulometria nos coeficientes de digestibilidade aparente da matéria seca e da proteína bruta das silagens, apesar da melhora numérica de $5 \%$ e $3,4 \%$ nos coeficientes de digestibilidade aparente da proteína e da matéria seca, respectivamente, quando o DGM das partículas da silagem foi reduzido de $2186 \mu \mathrm{m}$ para $979 \mu \mathrm{m}$. Mavromichalis et al. (2000) encontraram resultados semelhantes trabalhando com trigo integral para leitões.

Estes resultados diferem dos observados por de Giesemann et al. (1990), em estudo com sorgo e milho, no qual observaram que a redução do tamanho de partículas melhorou a digestibilidade aparente da matéria seca e da proteína para suínos em crescimento. Outros autores encontraram melhora na digestibilidade dos nutrientes para suínos com a redução no tamanho médio das partículas, quando trabalharam com cevada (Lawrence, 1970) e com trigo (Ivan et al., 1974).

Houve melhora no coeficiente de digestibilidade aparente do fósforo presente na silagem $(\mathrm{P}<0,05)$, enquanto para o cálcio a melhora foi observada apenas nas silagens com granulometrias fina e média $(\mathrm{P}<0,05)$, comparado com o milho seco. Estas respostas talvez estejam relacionadas com uma provável ação favorável do processo de ensilagem sobre as moléculas de fitato, aumentando a disponibilidade do fósforo e do cálcio. Além disso, alguns autores constataram que ácidos orgânicos podem melhorar a utilização do cálcio e fósforo em dietas para leitões desmamados e suínos em terminação (Han et al., 1998; Boling et al., 2000), devido à diminuição do $\mathrm{pH}$ estomacal.

Segundo Partane (2002) leitões jovens têm altas exigências nutricionais de fósforo e cálcio, e as fontes presentes na ração apresentam elevado poder tampão e resistem ao abaixamento do $\mathrm{pH}$ estomacal. Assim, a silagem de grãos úmidos de milho, devido ao seu menor valor de $\mathrm{pH}$, pode auxiliar a queda do $\mathrm{pH}$, determinando melhora na digestibilidade dos nutrientes.

Para o coeficiente de digestibilidade aparente do cálcio houve redução linear com o aumento do DGM das partículas da silagem $\left(\hat{\mathrm{Y}}_{\mathrm{i}}=104,6562\right.$ $\left.0,0187 \mathrm{X}_{\mathrm{i}}, \mathrm{R}^{2}=0,50\right)(\mathrm{P}<0,02)$. Esse efeito não foi verificado para o fósforo, mas houve melhora numérica de $11,6 \%$ no coeficiente de digestibilidade aparente, quando o DGM das partículas da silagem foi reduzido de $2186 \mu \mathrm{m}$ para $979 \mu \mathrm{m}$. 
Os valores de energia digestível das silagens foram maiores do que os do milho seco $(\mathrm{P}<0,05)$. As silagens nas granulometrias fina e média proporcionaram melhores valores de energia metabolizável em relação ao milho seco. Lima et al. (1999) verificaram que a fermentação anaeróbia da silagem de grãos úmidos de milho propicia um produto com alto valor energético para os suínos (energia digestível de 4070 a $4123 \mathrm{kcal} / \mathrm{kg} / \mathrm{MS}$ e energia metabolizável de 3929 a 3990kcal $/ \mathrm{kg} / \mathrm{MS}$ ). Estes resultados explicam a melhora na conversão alimentar dos leitões alimentados com silagens no experimento de desempenho.

A granulometria das silagens não influiu nos valores de ED e EM $(\mathrm{P}>0,05)$, apesar da diferença numérica de $170 \mathrm{kcal} / \mathrm{kg} / \mathrm{MS}$ e $200 \mathrm{kcal} / \mathrm{kg} / \mathrm{MS}$, respectivamente, quando o DGM das partículas da silagem passou de $2186 \mu \mathrm{m}$ para $979 \mu \mathrm{m}$.

Zanotto et al. (1998), ao trabalharem com suínos em crescimento e terminação observaram maiores valores de energia metabolizável quando o DGM do milho foi reduzido de $1026 \mu \mathrm{m}$ para $509 \mu \mathrm{m}$.

\section{CONCLUSÕES}

Nas rações de leitões na fase de creche, a silagem de milho úmido moído pode substituir totalmente

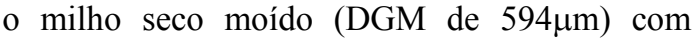
vantagens nutricionais, principalmente quando o DGM das partículas de silagem for de 979 e $1168 \mu \mathrm{m}$

\section{REFERÊNCIAS BIBLIOGRÁFICAS}

BERTO, D.A.; LOPES, A.B.F.C.; COSTA, C. Silagem de grãos úmidos para suínos. In: SIMPÓSIO SOBRE MANEJO E NUTRIÇÃO DE AVES E SUÍNOS E TECNOLOGIA DA PRODUÇÃO DE RAÇÕES, 2001, Campinas. Anais... Campinas: CBNA, 2001. p.203-218.

BOLING, S.D.; WEBEL, D.M.; MAVROMICHALIS, I. et al. The effects of citric acid on phytasephosphorus utilization in young chicks and pigs. $J$. Anim. Sci., v.78, p.682-689, 2000.

ENGELKE, G.L.; JURGENS, M.H.; SPEER, V.C. Performance of growing-finishing swine fed highmoisture or artificially dried corn in complete and free-choice diets. J. Anim. Sci., v.58, p.1307-1312, 1984.

GALYEAN, M.L.; GOODRICH, R.D.; OWENS, F.N. Corn particle size and site and extent of digestion by steers. J. Anim. Sci., v.49, p.204-210, 1979.

GIESEMANN, M.A.; LEWIS, A.J.; HANCOCK, J.D. et al. Effect of particle size of corn and grain sorghum on growth and digestibility by growing pigs. J. Anim. Sci., v.68, suppl. 1, p.104, 1990. (Abstr.).

HAN, Y.M.; RONEKER, R.; POND, W.G. et al. Adding wheat middlings, microbial phytase, and citric acid to corn-soybean meal diets for growing pigs may replace inorganic phosphorus supplementation. $J$. Anim. Sci., v.76, p.2649-2656, 1998.

HEALY, B.J.; HANCOCK, J.D.; KENNEDY, G.A. et al. Optimum particle size of corn and hard and soft sorghum for nursery pigs. J. Anim. Sci., v.72, p.22272236, 1994.

IVAN, M.; GILES, R.L.; ALIMON, A.R. et al. Nutritional evaluation of wheat. Anim. Prod., v.19, p.359-365, 1974.

LIMA, G.J.M.M., SOUZA, O.W.; BELLAVER, C. et al. Composição química e valor energético de silagem de grão de milho para suínos. Concórdia: Embrapa Suínos e Aves, 1999. 2p. (Comunicado Técnico, 240).

LOPES, A.B.R.C.; BERTO, D.A.; COSTA, C. et al. Grãos úmidos de milho ensilados com ou sem adição de propionato de cálcio para leitões na fase inicial. In: CONGRESSO LATINO AMERICANO DE SUINOCULTURA, 2002. Foz do Iguaçu. Anais... Foz do Iguaçu: Animal World, 2002a. 1 CD-ROM.

LOPES, A.B.R.C.; BERTO, D.A.; COSTA, C. et al. Silagem de grãos úmidos de milho para suínos na fase inicial dos 8 aos 30kg. Bol. Ind. Anim., v.58, p.181190, 2001a.

LOPES, A.B.R.C.; BERTO, D.A.; COSTA, C. et al. Silagem de grãos úmidos de milho para suínos nas fases de crescimento e terminação. Bol. Ind. Anim., v.58, p.191-200, 2001b.

LOPES, A.B.R.C.; LEONEL, M.; CEREDA, M.P. et al. Efeito do processo de ensilagem de grãos úmidos de milho nas características do amido. Braz. J. Food Technol., v.5, p.177-181, 2002b (Nota prévia).

MATTERSON, L.D.; POTTER, L.M.; STUTZ, N.W. et al. The Metabolizable energy of feed ingredients for chickens. Res. Report, v.7, p.3-11, 1965.

MAVROMICHALIS, I.; HANCOCK, J.D.; SENNE, B.D. et al. Enzyme supplementation and particle size of wheat in diets for nursery and finishing pigs. $J$. Anim. Sci., v.78, p.3086-3095, 2000. 
MELLO Jr., C.A. Processamento de grãos de milho e sorgo visando aumento do valor nutritivo. In: SIMPÓSIO SOBRE NUTRIÇÃO DE BOVINOS, 4., 1991, Piracicaba. Anais... Piracicaba: FEALQ, 1991. p.263-283.

NUMMER FILHO, I. Silagem de grão úmido de milho. In: SEMINÁRIO NACIONAL DE DESENVOLVIMENTO DA SUINOCULTURA, 9., 2001. Gramado, Anais... Gramado. Embrapa Suínos e Aves, 2001. p.29-43.

NUTRIENT requirements of swine. 20.ed. Washington: NRC, 1998. 189p.

OLIVEIRA, R.P.; FURLAN, A.C.; MOREIRA, I. et al. Valor nutritivo e desempenho de leitões alimentados com rações contendo silagem de grãos úmidos de milho. Rev. Bras. Zootec., v.33, p.164-156, 2004.

PARTANEN, K. Using organic acids in pig feeding as an alternative to antibiotic feed additives. In: SIMPÓSIO SOBRE MANEJO E NUTRIÇÃO DE AVES E SUÍNOS E TECNOLOGIA DA PRODUÇÃO DE RAÇÕES, 2002, Campinas. Anais... Campinas: CBNA, 2002. p.45-62.

PEKAS, J.C. Versatile swine laboratory apparatus for physiologic and metabolic studies. J. Anim. Sci., v.27, p.1301-1306, 1968.

SARTORI, J.R.; COSTA, C.; PEZZATO, A.C. et al. Silagem de grãos úmidos de milho na alimentação de frangos de corte. Pesq. Agropec. Bras., v.37, p.10091015,2002

SHAVER, R.D. Colheita e armazenamento de milho para a produção de silagem de alta qualidade para vacas leiteiras. In: NOVOS ENFOQUES NA
PRODUÇÃO E REPRODUÇÀO DE BOVINOS, 4., 2000. Passos. Anais... Passos: UNESP, 2000. p.63-66.

TABELA de composição química e valores energéticos para suínos e aves. 3.ed. Concórdia: Embrapa Suinos e Aves, 1991. 97p. (Documentos, 19).

THEURER, C.B. Grain processing effects on starch utilization by ruminants. J. Anim. Sci., v.63, p.16491662,1986

TÓFOLI, C.A.; BERTO, D.A.; TSE, M.L.P. et al. Avaliação nutricional da silagem de grãos úmidos de milho com diferentes teores de óleo para leitões na fase de creche. Arq. Bras. Med. Vet. Zootec., v.58, p.1206-1213, 2006.

USER'S guide: statistics. Version 6.12. Cary, NC: SAS Institute, 1998.

WONDRA, K.J.; HANCOCK, J.D.; BEHNKE, K.L. et al. Grinding, pelleting affects nutritional value of cereal grains, diets for swine. Feedstuff, v.68, p.13-17, 1996.

ZANOTTO, D.L.; GUIDONI, A.L.; LIMA, G.J.M.M. et al. Efeito da granulometria do milho sobre a digestibilidade das dietas para suinos em crescimento e terminação. Concórdia: Embrapa Suínos e Aves, 1998. 2p. (Comunicado Técnico, 223).

ZANOTTO, L.D.; BELlAVER, C. Método de determinação de granulometria de ingredientes para uso em rações de suínos e aves. Concórdia: Embrapa Suínos e Aves, 1996. p.1-5 (Comunicado Técnico, 215).

ZARDO, A.O.; LIMA, G.J.M.M. Alimentos para suínos. Concórdia: Embrapa Suínos e Aves, 1999 (Boletim Informativo, 12). 